\title{
Hydrodynamics and Mass Transfer Coefficients in a Bubble Column Photo- bioreactor
}

Onkar N. Manjrekar ${ }^{1 *}$, Yujian Sun, Lian He, Yinjie J Tang, Milorad P. Dudukovic ${ }^{1 *}$

${ }^{1}$ Department of Energy, Environmental and Chemical Engineering, Washington University in Saint Louis, Chemical Reaction Engineering Laboratory, Missouri, 63130, USA.

Correspondence email address:onkar.manjrekar@wustl.edu, dudu@wustl.edu 


\begin{abstract}
The present study compares typical measurements of bubble dynamics obtained with a 4-point optical probe over the same range of superficial gas velocity in the same size gas -liquid contactor in two different systems. The classical bubble column (BC) arrangement employed air bubbled through water. The photo-bioreactor (PBR) used a growing algae in appropriate culture solution. Local gas holdup distribution across the vessel was monitored, as well as the local distribution of bubble velocity, bubble chord length, bubble frequency and interfacial area per unit volume for both systems. It was observed these parameters were significantly different in the photo-bioreactor. This information coupled with the tracer absorption studies with oxygen provided the needed information to evaluate the gas liquid volumetric mass transfer coefficients from an appropriate model for both systems. The development of such a model is described. It was concluded that the difference in hydrodynamics of the two systems was due to difference in physicochemical properties.
\end{abstract}

Key Words: Bubble column photo-bioreactor, gas holdup, bubble velocity, volumetric mass transfer coefficient, gas-liquid interfacial area. 

Abbreviations
$\mathrm{BC}=$ Bubble column
CARPT $=$ Computer Automated Radioactive Particle Tracking
CFD = Computational Fluid Dynamics
CSTR $=$ Continuously Stirred Tank Reactor
$\mathrm{CT}=$ Computed Tomography
$\mathrm{DME}=$ Dimethyl Ether
$\mathrm{DO}=$ Dissolved Oxygen
OD = Optical Density
PBR $=$ Photobioreactor 


\section{Introduction}

Microalgae are rich in lipid content which makes them a potential valuable source of biofuels (Chisti, 2007; Georgianna and Mayfield, 2012; Greenwell et al., 2010). However, there are significant technological and commercial challenges in scaling-up to commercial production for either the systems that envision the use of open ponds or those relying on enclosed equipment (Mayfield and Wong, 2011). Microalgae are also potential sources of high-value products such as carotenes, omega-3 fatty acids, and pharmaceuticals (Cuellar-Bermudez et al., 2015; Markou and Nerantzis, 2013; Skjånes et al., 2012) (see Figure - 1). In order to commercially produce high-value chemicals from microalgae, it is necessary to cultivate them in a sterilized and wellcontrolled environment, such as photo-bioreactors. Preferred configurations for these reactors are bubble columns that enable recycle either with internal draft tubes, or coupling of external up-leg and down-leg (Luo, 2005; Xu et al., 2015). These reactors contain no moving parts, and hence microalgae are exposed to a mild shear stress environment. The successful design and scale-up of these photo-bioreactors is a key to the production of high-value compounds using microalgae (Luo, 2005).

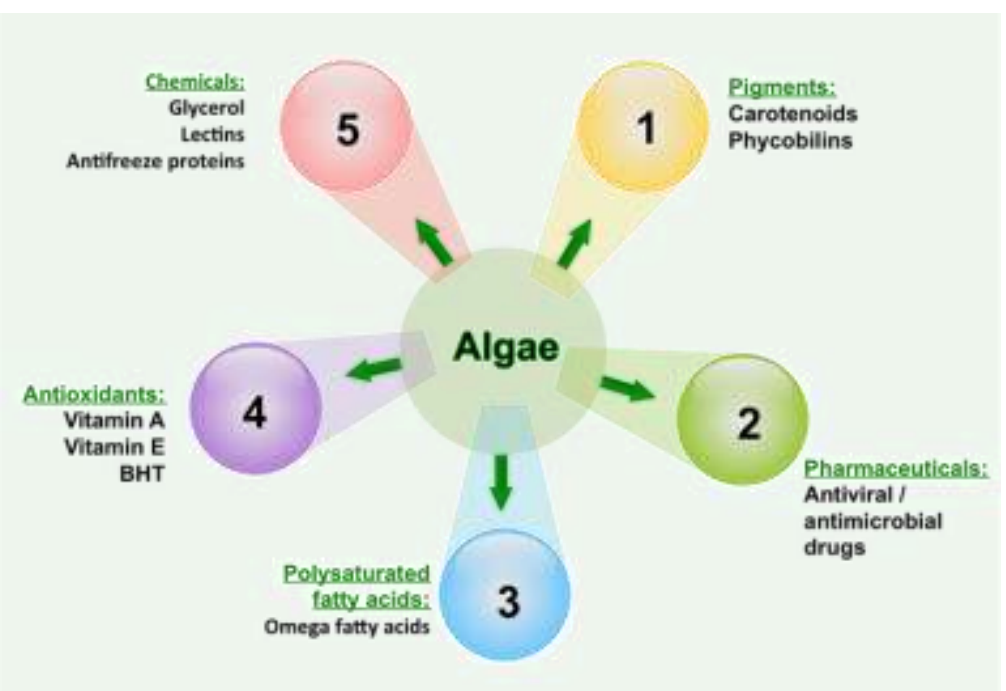

Figure-1: Applications of algae for production of high-value products 
For successful design and scale-up of a bubble column photo-bioreactor, it is necessary to develop at least a phenomenological model that captures the interactions of key parameters (Dudukovic, 2009; Dudukovic and Mills, 2014). For bubble columns appropriate models development has been illustrated by Degaleesan (1997), Gupta et al. (2001b), and Chen et al. (2006). The past success of the phenomenological models for prediction of bubble columns performance was partly due to the fact that the systems of interest (e.g., liquid phase methanol synthesis, dimethyl ether synthesis and Fischer Tropsch synthesis) were mostly operated in the churn turbulent flow regime which enabled validation of the key features such as radial distribution of bubble size and velocity to be accomplished with air water systems (Chen et al., 1998; Chen et al., 2005; Degaleesan et al., 1996; Gupta et al., 2001a; Jiang et al., 2015). In scaleup of bioreactors and photo-bioreactors, bubbly flow regime is often of interest, in which the effect of physicochemical properties of the liquid (slurry) can be much more pronounced on the measured quantities such as bubble size distribution and its motion (Clift et al., 1978). The presence of microorganisms in these systems modifies the properties of the liquid phase by excreting metabolites as they grow. Along with the metabolites, the $\mathrm{pH}$ of the liquid phase also changes during their growth, e.g. during shake flask growth of cyanobacterial algae the $\mathrm{pH}$ of the medium increases from 7.5 to about 9.5. To maintain optimum $\mathrm{pH}$ buffer solutions are added in the preparation of microalgae cultures. The electrolyte and hydroxyl compounds in the buffer solution are expected to alter bubble coalescence rates, which modify bubble dynamics (Joshi et al., 1998; Kantarci et al., 2005; Mudde, 2005; Mudde et al., 2009; Xiao et al., 2013). Hence, observations from air-water system cannot be directly extrapolated to scale-up these systems. To develop a scientific basis for scale- up of these reactors, it is of interest to begin to understand how bubble dynamics in such systems differ from those observed in air-water under similar hydrodynamic conditions and equipment of same size, and whether it changes with the cell 
culture density. Moreover one needs to assess whether the transport coefficients in such systems follow the previously established trends. Knowledge of transport coefficients is essential as the oxygen produced by algae in the photosynthesis must be efficiently removed from the liquid phase. Otherwise, excess dissolved oxygen in the liquid phase can suppress photosynthesis (De Mas et al., 1988; Torzillo et al., 1986). At present there are no reliable correlations that can predict a priori the effect of the many variables on bubble dynamics and resulting transport coefficients. Thus, one needs to establish what measurements are needed for improved understanding of the system.

In the past, Albdiri et al. (2015) applied 4-point optical probe to airlift bioreactor to study variation in gas hold-up and interfacial area along the height of the column, however systematic analysis of bubble velocities distribution, volumetric mass transfer coefficients and comparison in air-water system is lacking. In the past, Miron et al. (2000) have tested the applicability of existing correlations to predict overall gas hold-up and volumetric mass transfer coefficients for bubble column and air lift photo-bioreactor. It was observed that the overall gas holdup in a bubble column photo-bioreactor was accurately predicted using correlations by Chisti (1989) developed for bubble columns. For predicting gas holdup in airlift photo-bioreactor the correlations by Akita et al. (1994) could reasonably describe variations in overall gas holdup, however correlation by Kawase et al. (1995) and Miyahara et al. (1986) did not capture the trend, the empirical constants in these equation would need redefining to make reasonable predictions. To match the experimentally observed volumetric mass transfer coefficients, fitting of empirical parameter in the correlation proposed by Chisti (1989) was required for both bubble column and airlift photo-bioreactor. The inability of correlations to a priori predict design parameters without modifying empirical constants, highlights the necessity of experiments needed to further enhance the understanding of these systems. 
In this work, local bubble velocities and gas holdup were examined at several locations in a photo-bioreactor at a range of cell culture densities, and then compared to an air-water system. The bubble chord-length distributions and the gas-liquid interfacial area in a photo-bioreactor at different cell culture densities are then compared with values in air-water. Finally, the variation in volumetric mass transfer coefficient with cell culture density, and superficial gas velocity in a photo-bioreactor is discussed.

4-point optical probe was used to study bubble dynamics. Optical probe have become a favored tool for measuring local gas holdup, bubble frequency, chord length distribution and interfacial area distribution in bubble columns and other gas liquid contactors because they work reliably in opaque systems (Groen, 2004; Harteveld, 2005; Manjrekar, 2016; Mueller, 2010; Wu, 2007; Xue, 2004). Presently no theory is available for a priori prediction of the local bubble dynamic quantities, and their spatial distribution in the vessel of interest. Optical probes have been used successfully to study bubble dynamics in air-water systems, columns with vertical cooling internals and suspended solids (Hamed, 2012; Manjrekar and Dudukovic, 2015; Wu, 2007; Youssef et al., 2013). In this work we extend the application of optical probes to photobioreactors.

\subsection{Experimental Set-up:}

A bubble column reactor of $10 \mathrm{~cm}$ in diameter was used. For the air-water system, fresh tap water was the liquid phase, and air was the gas phase. The column was operated in a batch mode for the liquid phase. All experiments were performed at low superficial gas velocities (bubbly flow regime) ranging from $1 \mathrm{~cm} / \mathrm{s}$ to $3 \mathrm{~cm} / \mathrm{s}$ to maintain a low shear environment. The dynamic height of the system was maintained $115 \mathrm{~cm}$ above the sparger (aspect ratio of 11). A perforated plate distributor, with porosity of $0.05 \%$, was used in this work with 61 holes of $0.4 \mathrm{~mm}$ 
arranged in concentric circles. Experiments were performed at algae cell densities of $0.1 \mathrm{~g} / \mathrm{L}$, $0.17 \mathrm{~g} / \mathrm{L}$ and $0.2 \mathrm{~g} / \mathrm{L}$ (dried biomass weight). For the photo-bioreactor system, Synechocystis PCC 6803 was the cyanobacterial model strain. Batches of algae culture were first grown in a BG 11 medium in shake flasks at $30^{\circ} \mathrm{C}$ and $180 \mathrm{rpm}$ under continuous light illumination $(\sim 50$ $\mu$ mol photons $\cdot \mathrm{m}^{-2} \cdot \mathrm{s}^{-1}$ light) until one of the three selected cell mass densities was reached, and then transferred to the cylindrical PBR. The carbon dioxide enriched air was continuously bubbled into the bioreactor to provide $\mathrm{CO}_{2}$. The optical density was measured at a wavelength of $730 \mathrm{~nm}$ as an indicator of cell density. In preparation of culture a TES buffer solution (N[Tris(hydroxymethyl)methyl]-2-aminoethanesulfonic acid) was added to maintain the $\mathrm{pH}$ between 7.5 and 9 . Actual $\mathrm{pH}$ of the solution was found to be 8.2 and remained fairly constant over the cell culture densities used in this study.

\subsection{Measurement Techniques}

Bubble velocity can be determined with a high-speed camera, but only for transparent systems. In the present work, the effects of the culture density on bubble dynamics and gas-liquid interfacial area are studied with 4-point optical probe technique, which is useful for opaque systems such as PBR. For detailed description of the optical probe technique as implemented in our laboratory readers are referred to the work of Xue (2004).

The probe was positioned at four dimensionless radial locations $[\mathrm{r} / \mathrm{R}=0,0.5,0.75$ and 0.9$]$ along a straight line, with 0 representing the center of the column and 0.9 representing a position at $9 / 10$ of the inner column radius from the center that is close to the wall of the column. Figure 2 (a) shows the positioning and orientation of the probe inside the bubble column. The probe was oriented in a downward direction to capture bubbles traveling upward (Lee and Dudukovic, 2015). 
To obtain bubble dynamics using the algorithm developed by (Xue, 2004), the signal obtained from the probe must be binary, i.e., signal should only contain two voltages values, one representing gas phase and other representing the liquid phase. Figure 3 is a histogram of the signal over the collection time. It can be seen that the signals from both the air - water system and the photo-bioreactor are almost binary i.e., contain value around $1.8 \mathrm{~V}$ (liquid) and $3.6 \mathrm{~V}$ (gas) for both air water and photo-bioreactor (Lee and Dudukovic, 2014).

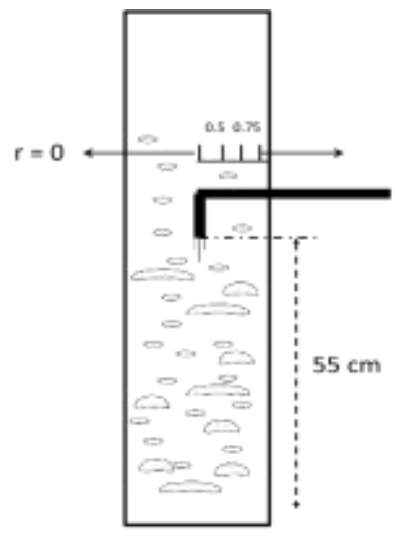

(a) Optical Probe

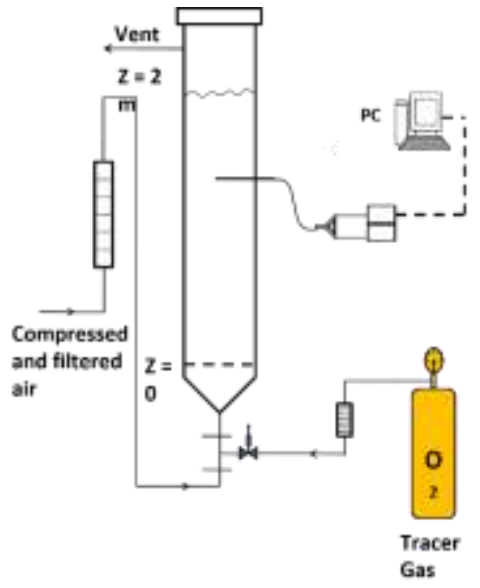

(b) Mass transfer experimental set - up

Figure - 2 Experimental setups (a) Location and orientation of optical probe (b) Experimental setup for mass transfer coefficient measurement.
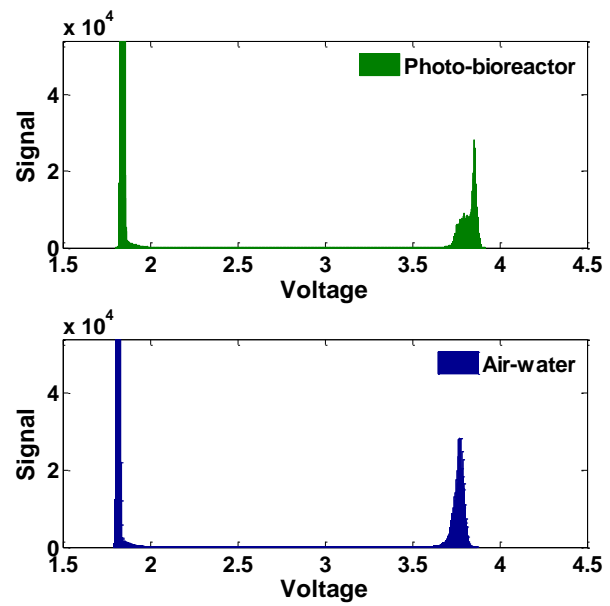

Figure - 3 Binary optical probe signal 
The mass transfer coefficients were measured using the dynamic gas oxygen-enriched-air method. The details of the method can be found in previous studies (Chang et al., 1989; Han and Al-Dahhan, 2007). The dissolved oxygen concentration [DO] was measured using an optical probe developed by Neo-Fox Ocean Optics, Florida, USA. The setup consists of the optical probe [model T1000], a light source, a spectrometer, a USB A/D converter, a PC, and software (Figure - 2 (b)). The DO concentration is obtained by measuring the fluorescence intensity with the spectrometer. The recorded signal exhibits a delay, and the concentration measured by the sensor $\mathrm{C}_{\text {sensor }}(\mathrm{t})$ at time $\mathrm{t}$ does not correspond to the actual DO concentration at that time $\mathrm{C}_{1}(\mathrm{t})$. The sensor response is assumed to be first order, and the probe constant $\mathrm{K}_{\text {sensor }}$ is calculated by the procedure described by Han and Al-Dahhan (2007). Once the probe constant $\mathbf{K}_{\text {sensor }}$ is known, the DO concentration $C_{1}(t)$ can be obtained using equation [1], suggested by (Han, 2007).

$$
C_{l}(t)=C_{\text {sensor }}(t)+\frac{1}{K_{\text {sensor }}} \frac{d C_{\text {sensor }}(t)}{d t}
$$

\subsection{Model for evaluation of the volumetric mass transfer coefficient}

To calculate the volumetric gas-liquid mass transfer coefficient, both a well mixed [CSTR] model and an axial dispersion model $[\mathrm{ADM}]$ are commonly used for the liquid phase when high gas velocities result in churn turbulent flow in the bubble column. (Akita and Yoshida, 1973; Han and Al-Dahhan, 2007; Lau et al., 2004; Vandu et al., 2004a, b). At low superficial gas velocities (bubbly flow regime), such models are unable to fit the observed concentration profile, as shown in Figure 4. 


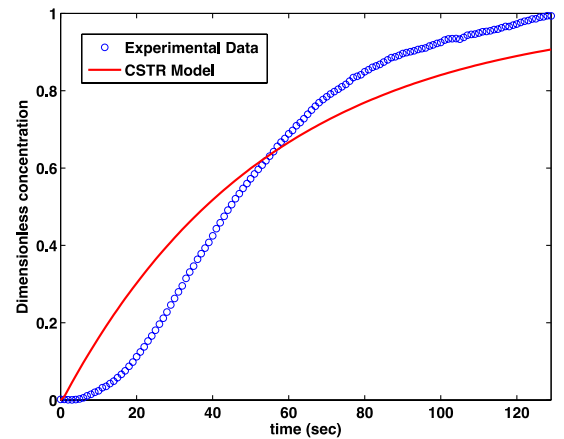

Figure - 4 Poor fit of the CSTR model to the measured tracer response

The traditional CSTR model overestimates early responses to step inputs of the tracer oxygen, since it assumes that mass transfer takes place at the same rate throughout the entire vessel immediately upon injection of the tracer at the bottom of the column. However, it takes time for the gaseous tracer to travel from the bottom to the top of the column (i.e., to replace the gas present in the reactor with oxygen enriched tracer gas) during which the part of the liquid phase that is not in contact with the gaseous tracer is not participating in mass transfer. The CSTR model agrees well with data only after the gaseous tracer "front," the moving cross section that roughly divides the column into two parts, one containing the oxygen and the other devoid of it, reaches the top of the column (i.e., all the oxygen depleted gas is replaced by oxygen enriched tracer gas).

To overcome the above shortcomings, the CSTR-PFR model is introduced in which the liquid phase is still assumed to be well mixed, but the gas phase is in plug flow. In this model, the tracer concentration in the gas phase at time $t$ is assumed uniform below the height $H_{g}(t)$, which is the height of the gaseous tracer "front" as illustrated in Figure 5. 


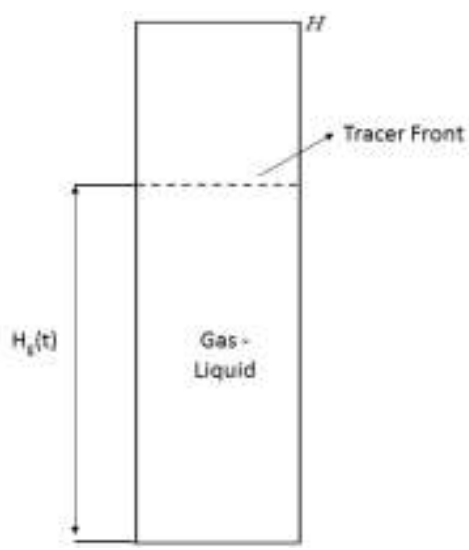

Figure 5. Schematic of the CSTR-PFR model.

Above $H_{g}(t)$ the gaseous tracer concentration is assumed to be zero, as is the rate of mass transfer. Thus, only part of the liquid phase is subject to mass transfer at a uniform rate as long as $H_{g}(t)<H$, the dynamic height of the bed. The volume of this liquid region is $A_{l} H_{g}(t)$, where $A_{l}$ is the cross-sectional area of the liquid phase, equal to the total volume of the liquid divided by $H$. Therefore, the mass balance equation for the tracer concentration in the liquid phase is formulated as follows:

$$
\begin{aligned}
& \frac{\partial C}{\partial t} A_{l} H=k_{l} a_{l}\left(C_{\text {sat }}-C\right) A_{l} H_{g}(t) \\
& H_{g}(t)= \begin{cases}u_{g} t \quad, \quad 0 \leq t \leq H / u_{g} \\
H \quad, \quad t \geq H / u_{g}\end{cases}
\end{aligned}
$$

where $a_{l}$ is interfacial area per unit volume of the liquid phase, and $u_{g}$ is the characteristic velocity of the gaseous tracer "front", which is approximated as the superficial gas velocity $U_{g}$, i.e.,

$$
u_{g}=U_{g}
$$


It is worth noting that the CSTR-PFR model is reduced exactly to the traditional CSTR model when $t \geq H / U_{g}$.

For the purpose of non-dimensionalization, let

$$
F=\frac{C}{C_{\mathrm{sat}}} \quad \text { and } \quad \theta=\frac{t}{\tau}
$$

where

$$
\tau=\frac{H}{U_{g}}
$$

Then, the dimensionless mass balance equation is

$$
\frac{\partial F}{\partial \theta}= \begin{cases}k_{l} a_{l} \tau(1-F) \theta & , \quad 0 \leq \theta \leq 1 \\ k_{l} a_{l} \tau(1-F) & , \quad \theta \geq 1\end{cases}
$$

The above ODE is easily solved with the initial condition $F(0)=0$ as,

$$
F(\theta)= \begin{cases}1-\exp \left(-k_{l} a_{l} \tau \cdot \frac{1}{2} \theta^{2}\right) & , \quad 0 \leq \theta \leq 1 \\ 1-\exp \left(-k_{l} a_{l} \tau \cdot\left(\theta-\frac{1}{2}\right)\right) & , \quad \theta \geq 1\end{cases}
$$

To validate the developed CSTR-PFR model, it was first used to fit the data from the tracer experiment operated under a superficial gas velocity of $2 \mathrm{~cm} / \mathrm{s}$. The dynamic bed height was measured to be $1.24 \mathrm{~m}$. The curve fitting was performed in MATLAB ${ }^{\circledR}$. The experimental and model-predicted F-curve is shown in Figure - $\mathbf{6}$ which illustrates that the CSTR-PFR model provides an excellent agreement with the experimental data for the entire range of $\theta$, including small values. The model is able to capture key features of the tracer curve at both the early and late stages of the tracer transfer process, and it can also capture correctly the inflection point on 
the curve which the traditional CSTR or ADM fail to do. Thus, the CSTR-PFR model developed in this work is adequate for determining mass transfer coefficients using tracer experiments.

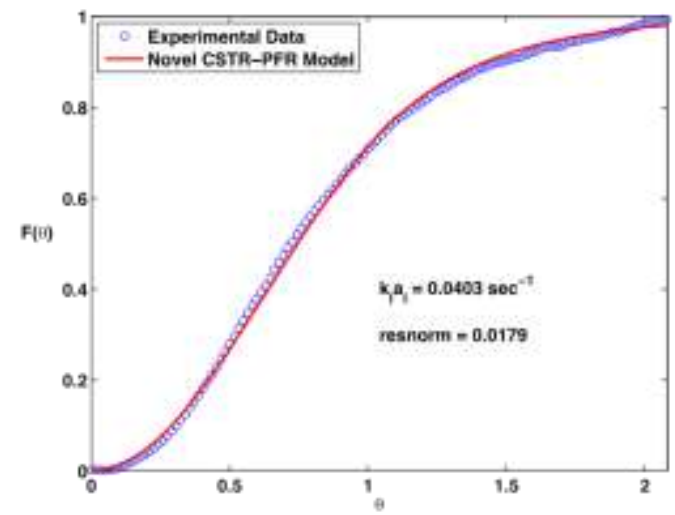

Figure 6. Experimental and model-predicted F-curve. $U_{g}=2 \mathrm{~cm} / \mathrm{s}, H=1.24 \mathrm{~m}$.

\section{Results and Discussion}

In this section, the effect of the cell culture density on bubble chord length distribution is described, followed by a discussion of observed changes in bubble chord length on bubble velocity, gas hold-up, bubble frequency, and gas-liquid interfacial area.

\subsection{Bubble chord length}

The parameters affecting bubble dynamics (bubble chord length, bubble velocity, gas holdup and gas-liquid interfacial area) in the bubble column reactor are dependent on each other. Bubble size is an important parameter which determines bubble velocity, gas-liquid interfacial area and gas holdup. With a 4-point optical probe, we can obtain the bubble chord length distribution, which is representative of the bubble size distribution (Mueller, 2010; Xue, 2004).

When gas is passed through an orifice into a pool of liquid, it breaks into bubbles, the size of which depends upon orifice diameter, gas velocity, fluid properties such as viscosity and surface tension at the interphase (Azzopardi et al., 2011). It is well-known that additional mixture components alter surface tension (Joshi et al., 1998; Kantarci et al., 2005; Mudde, 2005). For 
example, the average bubble size is reduced when alcohols or electrolytes are added to an airwater system. In preparing the microalgal culture for the photobioreactor, TES (N[Tris(hydroxymethyl)methyl]-2-aminoethanesulfonic acid) was used as the buffer solution. The addition of TES was expected to alter the bubble chord length distribution. It is evident from Figure 7 (A) that in the photobioreactor the average bubble chord length at the center of the column was reduced by $40-70 \%$, and at the wall of the column by $30-50 \%$, compared to an airwater system operated at identical superficial gas velocities. The effect of the increase in the cell culture density is not significant, as no observable change in bubble chord length is found (see Figure $7(\mathbf{B})$ ). Moreover, the bubble chord length distributions in a PBR compared to the airwater system are narrower in both the center and the wall region of the column, as shown in Figure 7 (C) and (D), respectively. (Standard deviation on means of bubble chord length in Figure-7, and their repeat runs to prove reproducibility are presented in Table-1of the appendix)

In the bubbly flow regime for the air-water system, when the superficial gas velocity is increased, the increase in the rate of bubble coalescence is larger than the increase in the rate of bubble breakup. Thus Figure 7 (a) shows an increase in the mean bubble chord length with an increase in the superficial gas velocity at all radial locations. In contrast, no significant change is observed in bubble chord length with superficial gas velocity in the PBR system.

For the air-water system, the bubble chord lengths are larger at the center of the column, as large bubbles formed by coalescence tend to move toward the center of the column due to the action of the lift force (Mudde, 2005). In the photo-bioreactor, the average bubble chord lengths are uniform throughout the cross-section of the column and are smaller than in the air-water system, due to reduced bubble coalescence. The lift force acting on the bubble is responsible for movement of the bubble towards the center of the column, which becomes significant beyond the 
critical size of $0.58 \mathrm{~cm}$. In present work we have a measure of bubble chord length which is representative measure of bubble size. No experimental tools are available to measure bubble size in $3 \mathrm{D}$ opaque system such as bubble column photo-bioreactor. Hence, comparing average bubble chord length in this work which is $0.2 \mathrm{~cm}$ with critical bubble size which is $0.58 \mathrm{~cm}$ we conclude that lift force acting on the bubbles towards the center of the column is not significant in photo-bioreactors (Harteveld, 2005). Hence, in absence of lift force driving bubbles to the center of the column, uniform bubble size distribution is observed in PBR.

It should be noted that in PBR, even though the average chord lengths are uniform throughout the cross-section their distribution is different in the center of the column and the wall region. The frequency of occurrence of bubbles is also different along the cross section of the column as later shown in Figure 9 (B). 

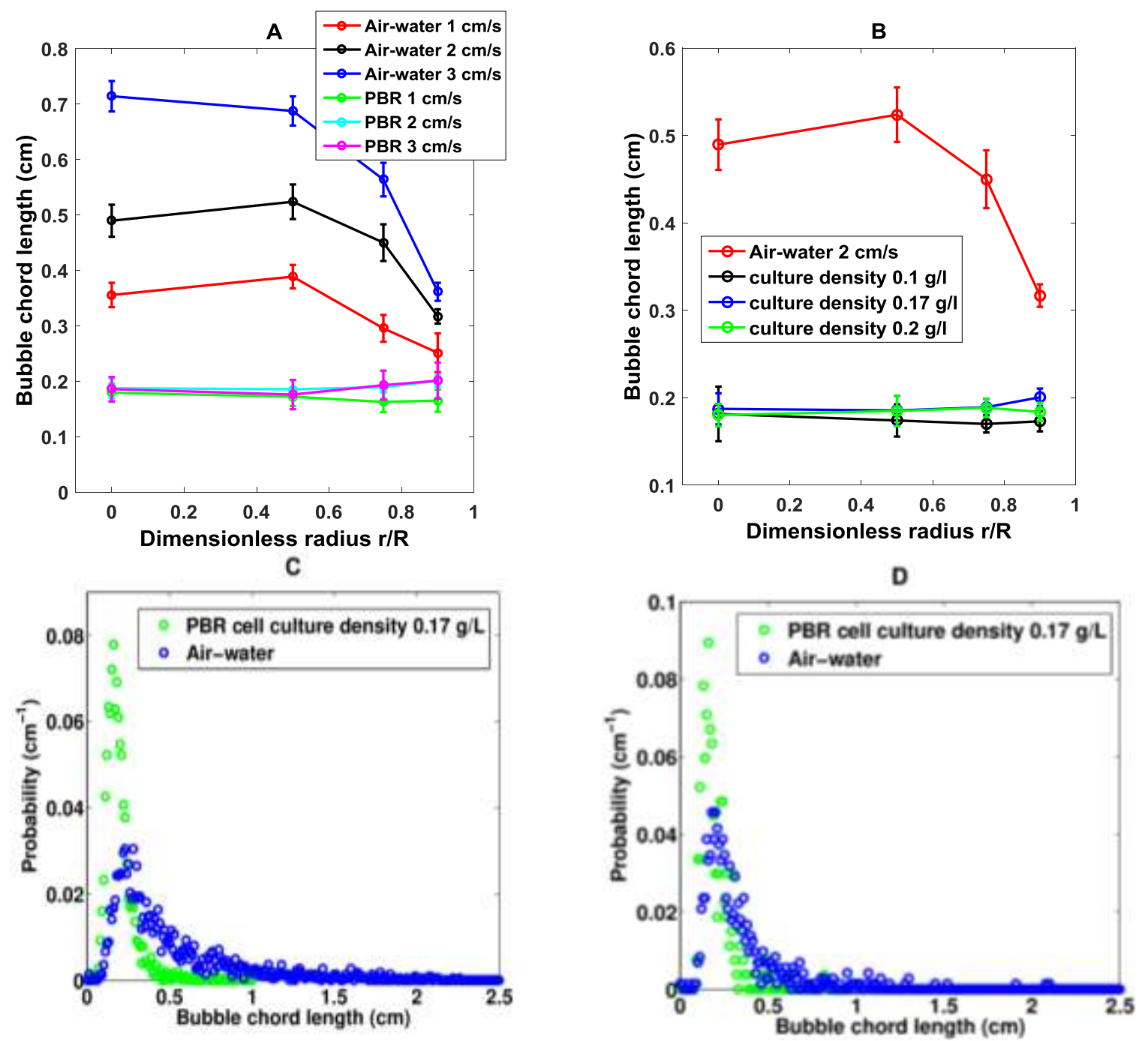

Figure 7 (A) Variation in bubble chord length with superficial gas velocity (cell culture density $0.17 \mathrm{~g} / \mathrm{L}$ ) (B) Variation in bubble chord length with culture density $(\mathrm{Ug}=2 \mathrm{~cm} / \mathrm{s})(\mathrm{C})$ Bubble chord length distribution at the center of the column $r / R=0(\mathrm{Ug}=2 \mathrm{~cm} / \mathrm{s})(\mathrm{D})$ Bubble chord length distribution near the wall of the column $\mathrm{r} / \mathrm{R}=0.9(\mathrm{Ug}=\mathbf{2} \mathrm{cm} / \mathrm{s})$

\subsection{Bubble velocity distribution in PBR}

As a consequence of change in the bubble chord length distribution, the bubble velocity distribution changes as well. Figure-8 compares the average bubble velocities and the distribution of bubble velocities in a PBR at the center of the column and at the wall region. Compared to the air water system, at identical superficial gas velocities, the average bubble velocities at the center of the column were reduced by $30-40 \%$; a similar reduction in the bubble velocity was observed in the wall region as well (see Figure-8 (A)). In the air-water system, the 
average velocity of bubbles is higher at the center of the column, because larger bubbles formed by coalescence tend to move toward the central region of the column and larger bubbles have larger rise velocities. However, in photobioreactors, the average bubble velocities do not vary with radial position, which is the result of reduced bubble coalescence causing more uniform bubble size. In the photo-bioreactor, there was no observable effect of increasing cell density on bubble velocity in the range we studied (see Figure-8 (B)). While Figure -8 (A) and (B) show changes in average bubble velocities, the changes in bubble velocity distribution at the center of the column, and near wall region are shown in Figure-8 (C) and (D) respectively. The bubble velocity distribution is broader for air water systems in both regions, which is a result of broader bubble size distribution in air-water system (Figure - 7 (C), (D)). (Standard deviation on means of bubble velocity presented in Figure-8, and their repeat runs to prove reproducibility are presented in Table-2 of the appendix.)

Along with the reduction in bubble chord length the presence of surface active agents is also responsible for reduction in bubble velocity. Surface active agents are present in a small amount so that there is no measurable change in the bulk property that can influence bubble velocity (Clift et al., 1978). These surface active agents form a viscous monolayer around the bubble which reduces internal circulation in the bubble, thereby significantly increasing drag and reducing bubble velocity (Harper, 1972). Levich (1962) proposed another mechanism for reduction in bubble velocity in presence of surfactants as follows. When a drop or bubble moves through a continuous medium, adsorbed surface active materials are swept to the rear leaving the frontal region uncontaminated. This concentration gradient results in the tangential gradient of the surface tension which in turn causes a tangential stress that tends to retard the motion. Along with the surface active agents micro-algae can also be adsorbed on the gas liquid interface which can cause reduction in internal circulation and reduce bubble velocity. In order to obtain a 
quantitative prediction of effect of surface active agents and micro algae on bubble velocity, very detailed measurements on gas-liquid interface surface tension and concentration of surface active agent at the interphase is required. However, it is very difficult to measure these quantities accurately and is beyond the scope of this work. We are pleased to illustrate here in our figures what magnitude effect one can expect.
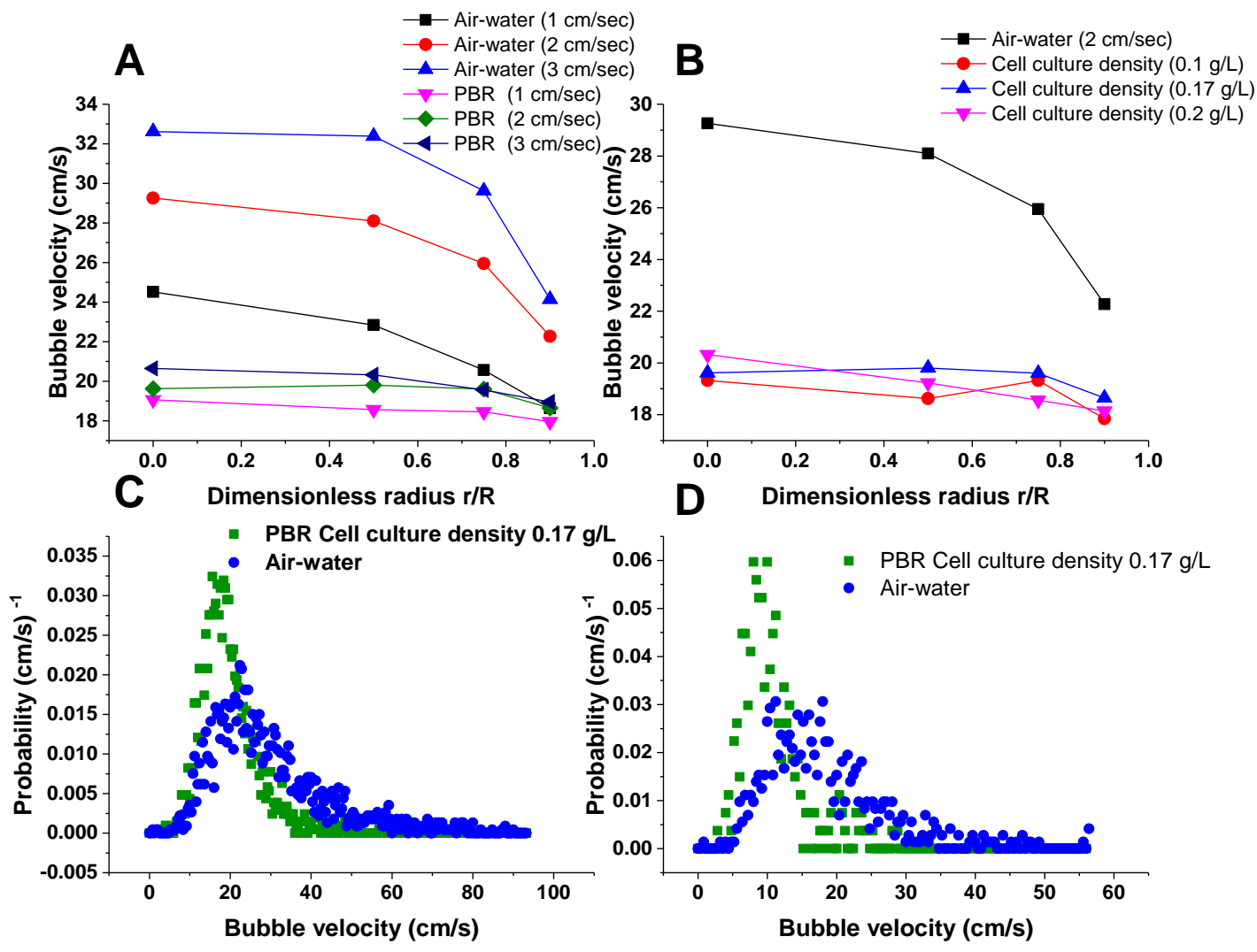

Figure 8 (A) Variation in bubble velocity with superficial gas velocity (cell culture density $0.17 \mathrm{~g} / \mathrm{L}$ ) (B) Variation in velocity with cell culture density $(\mathrm{Ug}=2 \mathrm{~cm} / \mathrm{s})(\mathrm{C})$ Bubble velocity distribution at the center of the column $r / R=0(U g=2 \mathrm{~cm} / \mathrm{s})(\mathrm{D})$ Bubble velocity distribution near the wall of the column $r / R=0.9(\mathrm{Ug}=$ $2 \mathrm{~cm} / \mathrm{s})$

\subsection{Bubble frequency}

Bubble frequency is determined as the number of signal jumps from the liquid phase to the gas phase per unit time in the optical signal. It is represents the number of gas-liquid interphases detected per unit time. In a non-coalescing medium, such as PBR, a larger number of smaller 
bubbles are present, which leads to higher density of gas-liquid interfaces. Hence, the bubble frequency was larger at all radial locations in a PBR compared to air water system (see Figure 9 (B)). The bubble frequency was higher at the center of the column, than near wall region, indicating even though the bubble size is uniform throughout the column more bubbles exist at the center of the column due to the lift force effect. The radial profiles of bubble frequency, gas hold up and interfacial area, and their variation with superficial gas velocity are strongly correlated (Xue, 2004). Hence, we can expect similar profiles for gas hold-up and interfacial area.

\subsection{Gas hold-up}

As shown in the Figure - 9 (A), radial gas hold-up profiles follow a trend similar to bubble freuency. The gas hold-up at the center of the column was found higher that near wall region. Even though the gas hold up profile is not flat, the diffeence between the gas hold-up at the center of the column and near the wall region is much less than what is observed in the churn turbulent flow regime (Kumar et al., 1997). Due to a reduction in the bubble velocity, the residence time of the gas phase in the PBR was increased, resulting in higher gas hold up compared to air-water system.

\subsection{Gas-liquid interfacial area}

Gas-liquid interfacial area was increased in PBR due to reduced bubble size and larger bubble number density. Figure - $\mathbf{9}$ (C) compares variation in gas-liquid interfacial area at cell culture density of $0.17 \mathrm{~g} / \mathrm{L}$. It shows that gas-liquid interfacial area was increased by about $60 \%$ at the central region, and about $20 \%$ in the wall region for the PBR. The radial variation of the gasliquid interfacial area follows similar trend to that observed for bubble frequency. The gas-liquid 
interfacial area decreases from the center of the column to the wall region, due to the lower bubble frequency in the wall region.
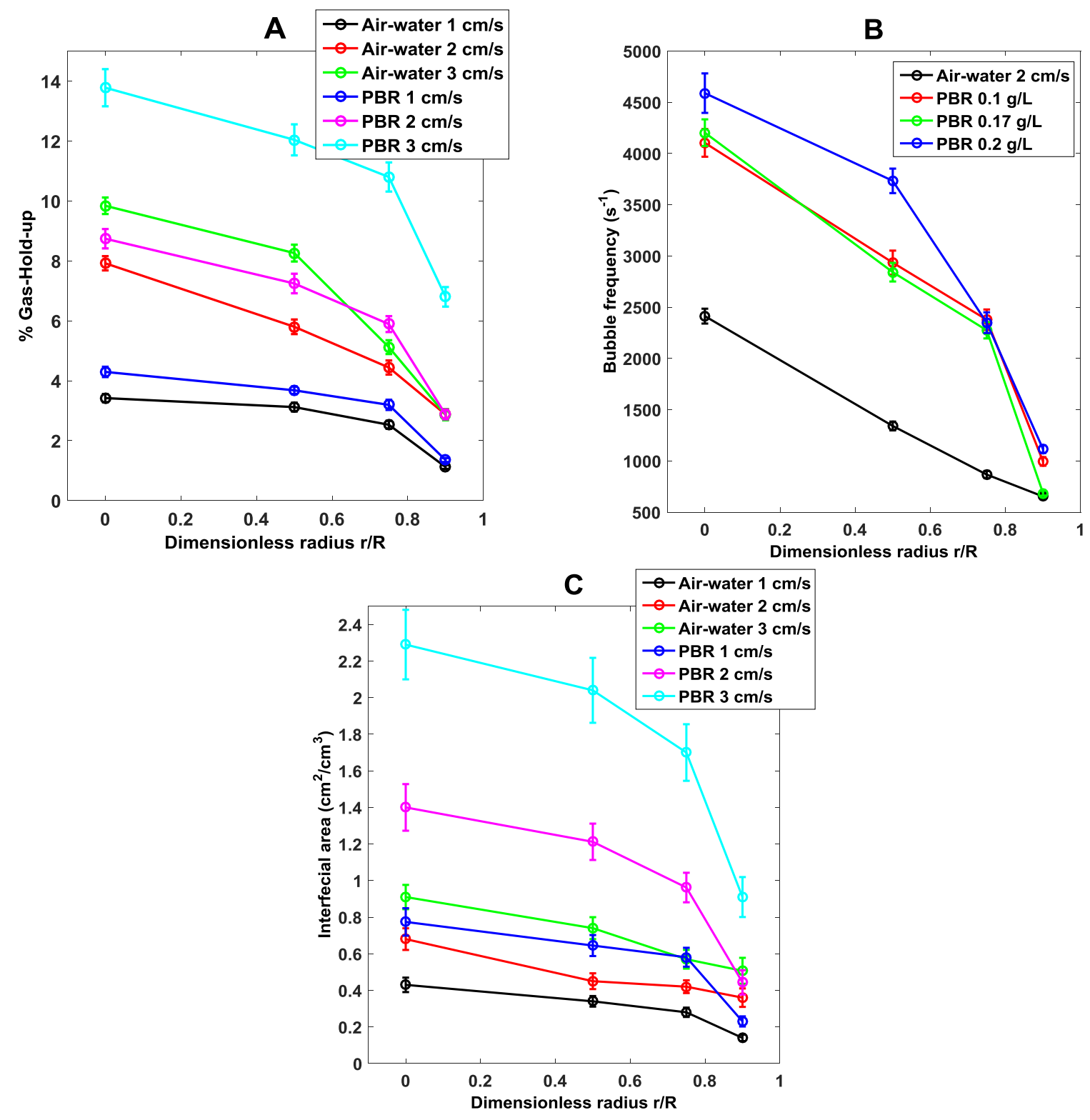

Figure 9: (A) Variation in radial gas holdup with superficial gas velocity (cell culture density $0.17 \mathrm{~g} / \mathrm{L}$ ) (B) Variation in bubble frequency with cell culture density at $\mathrm{Ug}=2 \mathrm{~cm} / \mathrm{s}(\mathrm{C})$ Variation in interfacial area concentration with cell culture density at $\mathrm{Ug}=2 \mathrm{~cm} / \mathrm{s}$ (cell culture density $0.17 \mathrm{~g} / \mathrm{L}$ )

The observed changes in bubble dynamics and the gas-liquid interfacial area in PBR, compared to the air-water system, are caused by the presence of algae, buffer solution and the difference in the $\mathrm{pH}$ of the liquid phase. As can be seen from earlier results, the increased cell culture density 
did not have a significant effect on either bubble dynamics or interfacial area concentration. Hence, to quantify the effect of buffer solution and alkaline $\mathrm{pH}$, an experiment was performed where the buffer solution was added to the air-water system and the $\mathrm{pH}$ of the solution was maintained close to that in a PBR $(\mathrm{pH} \approx 8.2)$. Figure 10 compares the results of the air-water system, PBR and air-water system with buffer solution at similar $\mathrm{pH}$ of the PBR. It is clear that bubble dynamics of the PBR and air-water with the buffer solution at similar $\mathrm{pH}$ are comparable. Table - 1 compares the averages of bubble velocity and bubble chord lengths at the center of the column for all three systems at superficial gas velocity of $2 \mathrm{~cm} / \mathrm{s}$. Based on the means and standard deviations, a t-test was performed. On the basis of the t-test, the mean bubble velocity and bubble chord length for the system with buffer solution and basic $\mathrm{pH}$ is different from both air-water system and PBR, at significance level of $\alpha=0.05$. The mean of bubble velocity and bubble chord length for system with buffer solutions are closer to PBR system. Based on these observations, we conclude that addition of buffer solution and alkaline $\mathrm{pH}$ significantly alters bubble dynamics of air-water system, and the addition of algae further changes bubble dynamics. The additional changes in bubble dynamics would be due to presence of algae and metabolites in the system.

Table - 1 Average bubble velocity and bubble chord length at the center of the column $(\mathrm{Ug}=2 \mathrm{~cm} / \mathrm{sec})$

\begin{tabular}{|c|c|c|c|c|c|c|}
\hline & \multicolumn{2}{|c|}{ Bubble velocity (cm/sec) } & \multicolumn{3}{|c|}{ Bubble chord length (cm) } \\
\hline & AW & PBR & $\begin{array}{c}\text { Buffer } \\
\text { solution }\end{array}$ & AW & PBR & $\begin{array}{c}\text { Buffer } \\
\text { solution }\end{array}$ \\
\hline Average & 32.640 & 19.522 & 21.269 & 0.808 & 0.191 & 0.236 \\
\hline $\begin{array}{c}\text { Standard } \\
\text { deviation }\end{array}$ & 0.190 & 0.034 & 0.976 & 0.050 & 0.005 & 0.024 \\
\hline
\end{tabular}




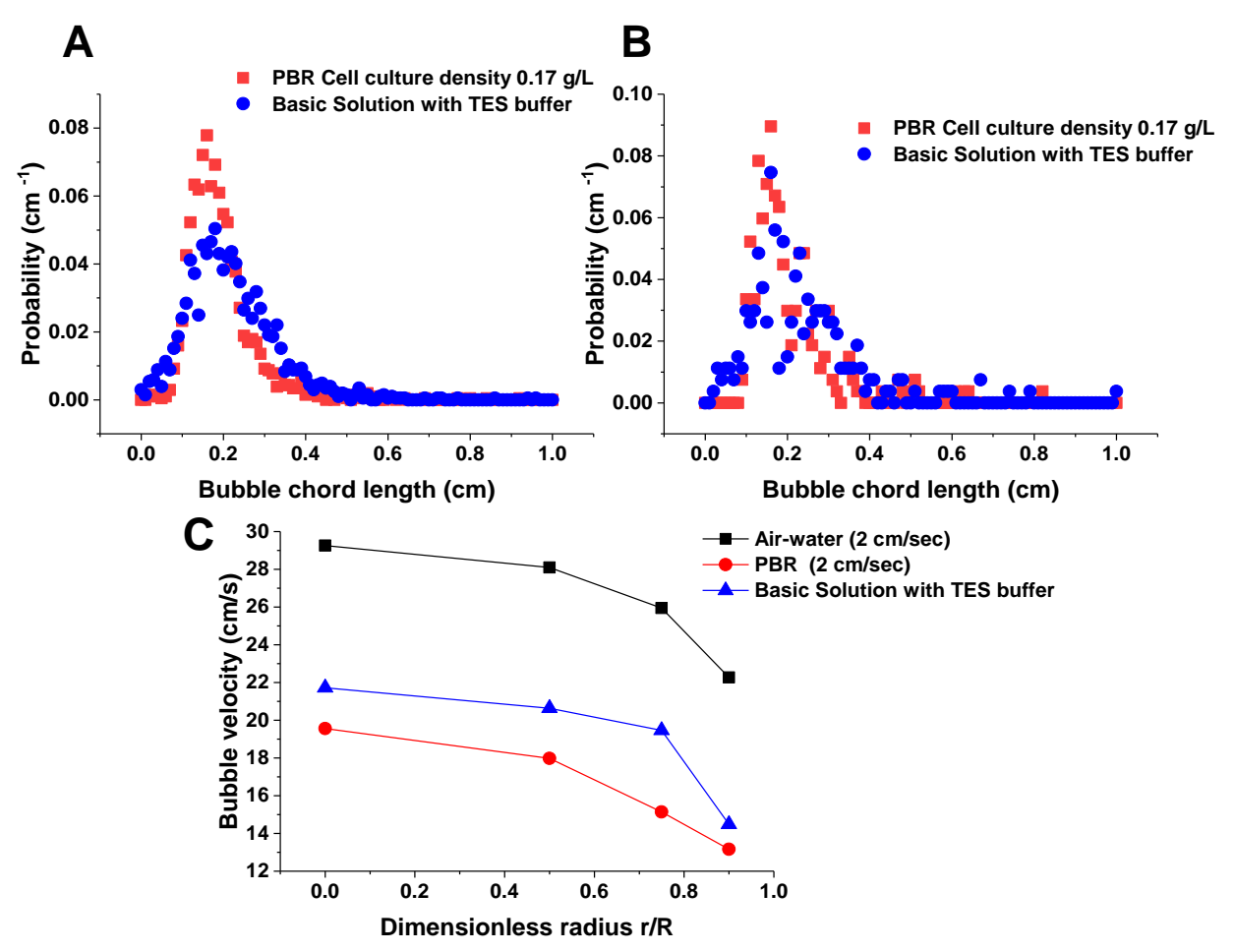

Figure 10: (A) Bubble chord length distribution at the center of the column $r / R=0(U g=2 \mathrm{~cm} / \mathrm{s})(B)$ Bubble chord length distribution at the wall of the column $r / R=0.9(\mathrm{Ug}=2 \mathrm{~cm} / \mathrm{s})(\mathrm{C})$ Comparison of bubble velocity with air-water system, PBR and Basic solution with TES buffer $(\mathrm{Ug}=2 \mathrm{~cm} / \mathrm{s})$

\subsection{Volumetric mass transfer coefficients}

The difference in the hydrodynamics between air-water system and PBR are expected to be reflected in the interphase transport coefficients. Volumetric mass transfer coefficients in the airwater system and photo-bioreactor are compared in Figure - 11, where a significant increase in the volumetric mass transfer coefficient $\left(\mathrm{k}_{1} \mathrm{a}\right)$ in the photo-bioreactor is observed. The increase in gas-liquid interfacial area concentration is responsible for this increase in the volumetric mass transfer coefficient. To support this, average gas-liquid interfacial area for air-water system and PBR was calculated from measured radial distribution of gas liquid interfacial area at superficial gas velocity of $1 \mathrm{~cm} / \mathrm{s}, 2 \mathrm{~cm} / \mathrm{s}$ and $3 \mathrm{~cm} / \mathrm{s}$ (cell culture density $0.17 \mathrm{~g} / \mathrm{L}$ ). As shown in Figure -12, gas liquid interfacial area in PBR is much larger compared to air water system. The volumetric mass transfer coefficient $\mathrm{k}_{1} \mathrm{a}$ is a combination of two parameters, the mass transport 
coefficient $\mathrm{k}_{1}$ and interfacial area concentration $a$ (interfacial area per unit volume of the gasliquid mixture, $\mathrm{m}^{2} / \mathrm{m}^{3}$ ). It is noted that $a$ and $a_{l}$ (interfacial area per unit volume of liquid) differ by a factor of liquid holdup i.e., $a=a_{l} \varepsilon_{l}$. A reduction in the bubble chord length increases the interfacial area concentration. At the same time, a reduction in the bubble chord length reduces the bubble velocity, which increases the contact time of the bubbles (defined in bubble columns as the ratio of bubble diameter to bubble velocity) with the liquid phase (Nedeltchev et al., 2007, 2010). According to penetration theory and surface renewal theory, contact time is inversely proportional to mass transfer coefficients. Hence a reduction in the bubble velocity will reduce the mass transport coefficient $\mathrm{k}_{1}$. However, the overall change in the volumetric mass transfer coefficient depends on the relative change in the mass transport coefficient and interfacial area concentration. Whether it will increase or decrease depends on which term dominates (Manjrekar and Dudukovic, 2013). In this work the increase in interfacial area is larger compared to reduction in the mass transport coefficient $\mathrm{k}_{\mathrm{l}}$, hence a significant increase in the overall mass transfer coefficient $\mathrm{k}_{\mathrm{l}} \mathrm{a}$ is observed in the photo-bioreactor.

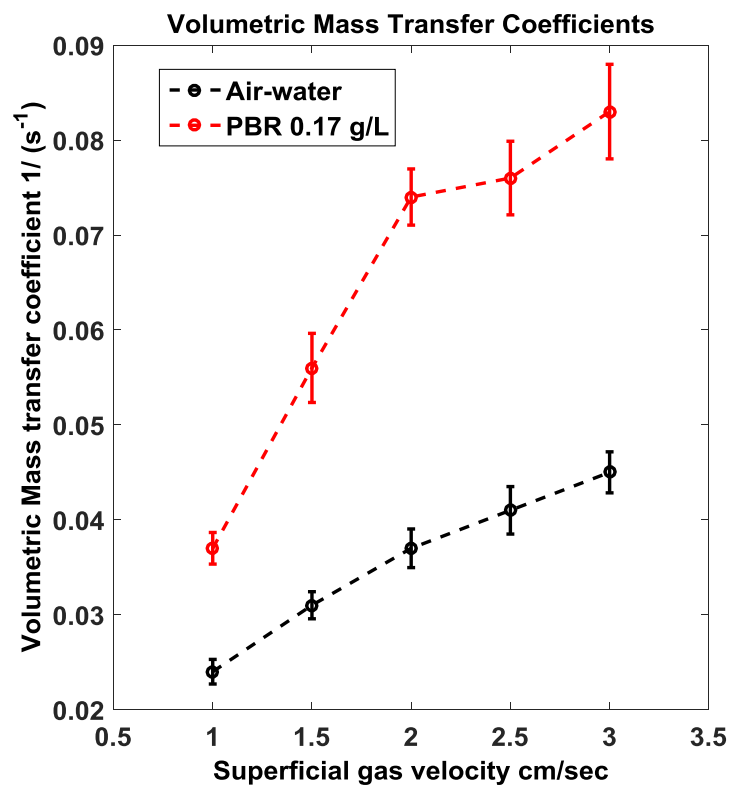

Figure - 11 Variation of volumetric mass transfer coefficient with superficial gas velocity 


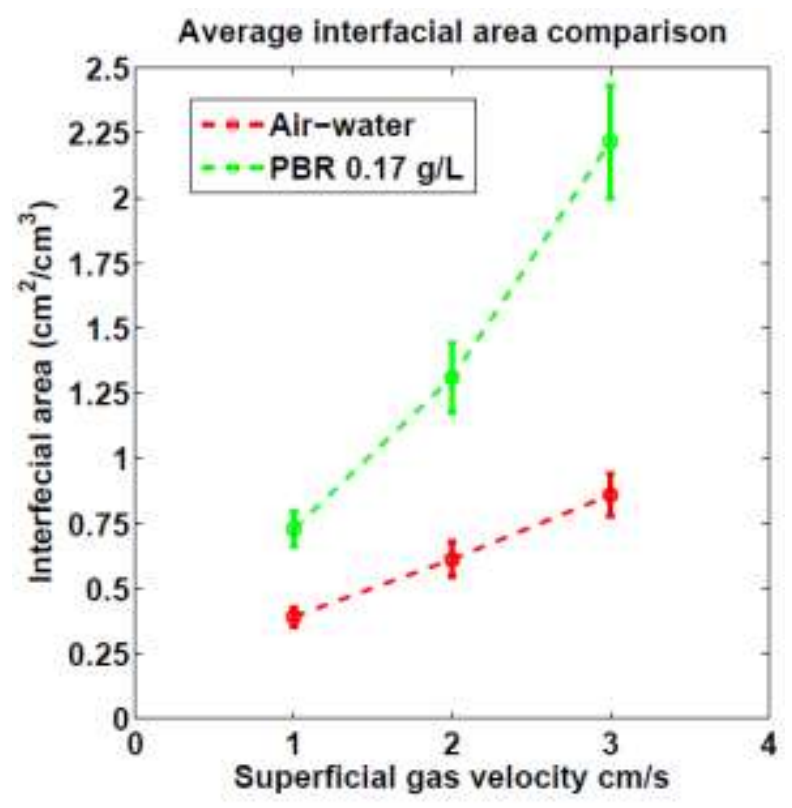

Figure - 12 Variation of average interfacial area with superficial gas velocity

\section{Concluding remarks}

This work illustrates the application of a 4-point optical probe technique to study bubble dynamics in a photo-bioreactor.

- The bubble dynamics in photo-bioreactors (PBR) is different from those in an air-water system, mainly because of the presence of buffer solution in the photo-bioreactor, the difference in the $\mathrm{pH}$ of the liquid phase, and the presence of algae.

- An increase in the gas-liquid interfacial area in a PBR increases the volumetric mass transfer coefficients. In order to predict volumetric mass transfer coefficients using correlations in photo-bioreactor, it is essential to have accurate information of properties of the liquid phase in photo-bioreactor such as viscosity and surface tension. To the best of our knowledge such values for the system used in this work are not available in open literature. This makes it difficult to predict these parameters using correlations. Additional experiemenatl values are needed coupled with, advanced correlation developed using machine learning tools. 
- No effect of an increase in the cell culture density of the solution was found over the range investigated $(0.1 \mathrm{~g} / \mathrm{L}$ to $0.2 \mathrm{~g} / \mathrm{L})$. In the industrial production of micro algae typical cell culture density is of the order of 0.3-0.5 g/L (Klinthong et al., 2015) . Typical cell culture density for bubble column, airlift and flat plate bioreactor at low end ranges from 0.03 to $0.28 \mathrm{~g} / \mathrm{L}$ (Bosma et al., 2007; Hanagata et al., 1992; Henrard et al., 2011; Jacob-Lopes et al., 2009; Richmond and Cheng-Wu, 2001) and at high range from 2 to 4 g/L (de Morais and Costa, 2007; Krichnavaruk et al., 2007). The cell culture densities used in this work range from $0.1 \mathrm{~g} / \mathrm{L}$ to 0.2 $\mathrm{g} / \mathrm{L}$ which is not far away from typical low end industrial cell culture density. The micro-algae are typically of size 1 to 20 microns [Stokes' number [St] $<<1]$ hence, the mixture of micro-algae in the photo-bioreactor can be treated as a pseudo homogenous liquid phase. When Stokes' number $[\mathrm{St}]<<1$ the particles (algae) align along the stream lines of the bubble without interacting with them (Hooshyar et al., 2013). Hence, in the range investigated we did not find an effect of increase in cell culture density on the hydrodynamics. It was expected that at high cell culture density used in this work the bubble dynamics would differ due to the presence of metabolites from algae growth. Based on our experimental results we believe that the gas-liquid interfaces in the bubble column are already saturated with surface active contaminants and hence an addition of additional metabolites or algae cells does not impact the hydrodynamics. This finding implies that the properties of the bubble dynamics, including the interfacial area concentration, will not affect transport coefficients much during algae growth, as long as assumption of pseudo-homogenous liquid phase is valid.

- $\quad$ The present work introduces the CSTR-PFR model to predict volumetric mass transfer coefficients in the bubbly flow regime. The model considers time required to replace all the gas present in the reactor with oxygen enriched tracer gas. This modification gave better prediction for tracer response in flow regime of interest in this work. Such a modification was not 
previously used for prediction of mass transfer coefficients in churn turbulent flow regime as time required for replace all the gas present in the reactor with oxygen enriched tracer gas is much lower compared to bubbly flow regime.

- The key bubble column parameters [gas holdup profile, bubble velocity, and volumetric mass transfer coefficient] evaluated here can be used for validation of CFD results, which can later be combined with an algae growth model in a scale-up analysis (Chen et al., 2004).

\section{Acknowledgements}

This study was made possible by the financial support of the members of the Slurry Bubble Column Consortium [SBCR-CAE], Eni [Italy], Johnson Matthey [U.K.], Sasol [South Africa] and Statoil [Norway]. Authors would also like to thank Energy Environmental and Chemical Engineering department, Washington University and National Science Foundation (CBET 1438125) for their financial support.

\section{Notations}

$\mathrm{a}=$ Gas liquid interfacial area based on dispersion volume $\left(\mathrm{m}^{2} / \mathrm{m}^{3}\right)$

$\mathrm{a}_{\mathrm{L}}=$ Gas liquid interfacial area based on liquid phase volume $\left(\mathrm{m}^{2} / \mathrm{m}^{3}\right)$

$A_{l}=$ Cross-sectional area of the liquid phase

$\mathrm{BC}=$ Bubble column

$\mathrm{C}=$ Concentration of gaseous tracer

$\mathrm{F}=$ Dimensionless gaseous tracer concentration

CSTR $=$ Continuously stirred tank reactor

$\mathrm{DO}=$ Dissolved oxygen

$\mathrm{H}_{\mathrm{g}}(\mathrm{t})=$ Height of gaseous tracer front

$\mathrm{k}_{\mathrm{L}} \mathrm{a}=$ Overall liquid side volumetric mass transfer coefficient based on dispersion volume

$\mathrm{k}_{\mathrm{L}} \mathrm{a}_{\mathrm{L}}=$ Overall liquid side volumetric mass transfer coefficient based on liquid phase volume $\mathrm{N}=$ The total number of gas liquid interfaces passing by the probe during the measurement time 
$\mathrm{R}=$ Radius of the column

$r=$ Distance from the center of the column

$\mathrm{u}_{\mathrm{g}}=$ Characteristic tracer front velocity

$\mathrm{U}_{\mathrm{g}}=$ Superficial gas velocity

$\theta=$ Dimensionless time 


\section{Appendix}

Table - 1 Means and standard deviation of bubble chord length at Center and Wall

\begin{tabular}{|c|c|c|c|}
\hline \multicolumn{4}{|c|}{ Column center bubble chord length $(r=0.0)$} \\
\hline $\begin{array}{l}\text { Superficial gas } \\
\text { velocity } \mathrm{cm} / \mathrm{sec}\end{array}$ & $\begin{array}{l}\text { Average } \\
\text { value cm }\end{array}$ & $\begin{array}{c}\text { Standard } \\
\text { Deviation of } \\
\text { distribution }\end{array}$ & $\begin{array}{l}\text { Standard deviation of } \\
\text { repeat runs* }\end{array}$ \\
\hline 1 ( Air-water) & 0.36 & 0.286 & 0.022 \\
\hline 2 (Air-water) & 0.489558 & 0.4209 & 0.02889 \\
\hline 3 (Air-water) & 0.7141 & 0.637 & 0.0274 \\
\hline 1 (Photo-bioreactor) & 0.179 & 0.07383 & 0.00164 \\
\hline 2 (Photo-bioreactor) & 0.187 & 0.08287 & 0.00178 \\
\hline 3 (Photo-bioreactor) & 0.185 & 0.075953 & 0.0022 \\
\hline \multicolumn{4}{|c|}{ Column wall bubble chord length $(r=0.9)$} \\
\hline $\begin{array}{l}\text { Superficial gas } \\
\text { velocity } \mathrm{cm} / \mathrm{sec}\end{array}$ & $\begin{array}{l}\text { Average } \\
\text { value cm }\end{array}$ & $\begin{array}{c}\text { Standard } \\
\text { Deviation of } \\
\text { distribution }\end{array}$ & $\begin{array}{l}\text { Standard deviation of } \\
\text { repeat runs* }\end{array}$ \\
\hline 1 ( Air-water) & 0.278 & 0.18 & 0.035 \\
\hline 2 (Air-water) & 0.35 & 0.23461 & 0.0129 \\
\hline 3 (Air-water) & 0.381 & 0.259 & 0.0163 \\
\hline 1 (Photo-bioreactor) & 0.164 & 0.065 & 0.02 \\
\hline 2 (Photo-bioreactor) & 0.187 & 0.1 & 0.01 \\
\hline 3 (Photo-bioreactor) & 0.1818 & 0.0927 & 0.00327 \\
\hline
\end{tabular}

* Three repeat runs were performed for each measurement, mean value of each set of distribution was calculated to obtain standard deviation. 
Table -2 Means and standard deviation of bubble velocity at Center and Wall

\begin{tabular}{|c|c|c|c|}
\hline \multicolumn{4}{|c|}{ Column center bubble velocity $(r=0)$} \\
\hline $\begin{array}{l}\text { Superficial gas } \\
\text { velocity } \mathrm{cm} / \mathrm{sec}\end{array}$ & $\begin{array}{c}\text { Average } \\
\text { value } \mathrm{cm} / \mathrm{sec}\end{array}$ & $\begin{array}{c}\text { Standard } \\
\text { Deviation of } \\
\text { distribution }\end{array}$ & $\begin{array}{l}\text { Standard deviation of } \\
\text { repeat runs* }\end{array}$ \\
\hline 1 ( Air-water) & 24.34 & 14.541 & 0.654 \\
\hline 2 (Air-water) & 29.26 & 15.31 & 0.453 \\
\hline 3 (Air-water) & 32.67 & 17.41 & 0.795 \\
\hline 1 (Photo-bioreactor) & 18.864 & 6.864 & 0.466 \\
\hline 2 (Photo-bioreactor) & 19.56 & 7.5372 & 0.619 \\
\hline 3 (Photo-bioreactor) & 20.85 & 7.57 & 0.309 \\
\hline \multicolumn{4}{|c|}{ Column wall bubble velocity $(r=0.9)$} \\
\hline $\begin{array}{l}\text { Superficial gas } \\
\text { velocity } \mathrm{cm} / \mathrm{sec}\end{array}$ & $\begin{array}{c}\text { Average } \\
\text { value } \mathrm{cm} / \mathrm{sec}\end{array}$ & $\begin{array}{c}\text { Standard } \\
\text { Deviation of } \\
\text { distribution }\end{array}$ & $\begin{array}{l}\text { Standard deviation of } \\
\text { repeat runs* }\end{array}$ \\
\hline 1 ( Air-water) & 19.07 & 10.465 & 0.6 \\
\hline 2 (Air-water) & 22.87 & 10.6633 & 0.31 \\
\hline 3 (Air-water) & 25.13 & 13.42 & 0.849 \\
\hline 1 (Photo-bioreactor) & 18.123 & 7.484 & 0.6516 \\
\hline 2 (Photo-bioreactor) & 18.614 & 8.1035 & 0.6368 \\
\hline 3 (Photo-bioreactor) & 19.34 & 8.233 & 0.5875 \\
\hline
\end{tabular}




\section{References}

- $\quad$ Akita, K., Nakanishi, O., Tsuchiya, K., 1994. Turn-around energy losses in an external-loop airlift reactor. Chemical Engineering Science 49, 2521-2533.

- Akita, K., Yoshida, F., 1973. Gas Holdup And Volumetric Mass-Transfer Coefficient In Bubble Columns - Effects Of Liquid Properties. Industrial \& Engineering Chemistry Process Design and Development 12, 76-80.

- Albdiri, A.D.Z., Ojha, A., Al-Dahhan, M., 2015. Study of Local Gas Holdup and Specific Interfacial Area in a Split-Column Airlift Bioreactor Using Sphosticated 4-Point Optical Probe for Culturing Microlgae/Cyanobacteria. Chemical Engineering Communications 202, 892-898.

- Azzopardi, B.J., Mudde, R.F., Lo, S., Morvan, H., Yan, Y., Zhao, D., 2011. Bubble Columns, Hydrodynamics of Gas-Liquid Reactors. John Wiley \& Sons, Ltd, pp. 3-59.

- Bosma, R., van Zessen, E., Reith, J.H., Tramper, J., Wijffels, R.H., 2007. Prediction of volumetric productivity of an outdoor photobioreactor. Biotechnology and Bioengineering 97, 1108-1120.

- Chang, H.N., Halard, B., Mooyoung, M., 1989. Measurement Of Kla By A Gassing-In Method With Oxygen-Enriched Air. Biotechnology and Bioengineering 34, 1147-1157.

- Chen, J.W., Gupta, P., Degaleesan, S., Al-Dahhan, M.H., Dudukovic, M.P., Toseland, B.A., 1998. Gas holdup distributions in large-diameter bubble columns measured by computed tomography. Flow Measurement and Instrumentation 9, 91-101.

- Chen, P., Gupta, P., Dudukovic, M.P., Toseland, B.A., 2006. Hydrodynamics of slurry bubble column during dimethyl ether (DME) synthesis: Gas-liquid recirculation model and radioactive tracer studies. Chemical Engineering Science 61, 6553-6570.

- Chen, P., Sanyal, J., Dudukovic, M.P., 2005. Numerical simulation of bubble columns flows: effect of different breakup and coalescence closures. Chemical Engineering Science 60, 10851101.

- Chisti, Y., 1989. Airlift bioreactors. Elsevier, London.

- Chisti, Y., 2007. Biodiesel from microalgae. Biotechnology Advances 25, 294-306.

- Clift, R., Grace, J.R., Weber, M.E., 1978. Bubbles Drops and Particles. Acadamic Press, New York.

- Cuellar-Bermudez, S.P., Aguilar-Hernandez, I., Cardenas-Chavez, D.L., Ornelas-Soto, N., Romero-Ogawa, M.A., Parra-Saldivar, R., 2015. Extraction and purification of high-value metabolites from microalgae: essential lipids, astaxanthin and phycobiliproteins. Microbial Biotechnology 8, 190-209. 
- De Mas, C., Jansen, N.B., Tsao, G.T., 1988. Production of optically active 2,3-butanediol by Bacillus polymyxa. Biotechnology and Bioengineering 31, 366-377.

- de Morais, M.G., Costa, J.A.V., 2007. Carbon dioxide fixation by Chlorella kessleri, C. vulgaris, Scenedesmus obliquus and Spirulina sp. cultivated in flasks and vertical tubular photobioreactors. Biotechnology Letters 29, 1349-1352.

- Degaleesan, S., 1997. Turbulence and Liquid Mixing in Bubble Columns, Ph.D Thesis. Washington University in St. Louis, Saint Louis, MO, USA.

- Degaleesan, S., Roy, S., Kumar, S.B., Dudukovic, M.P., 1996. Liquid mixing based on convection and turbulent dispersion in bubble columns. Chemical Engineering Science 51, $1967-$ 1976.

- Dudukovic, M.P., 2009. Frontiers in Reactor Engineering. Science 325, 698-701.

- Dudukovic, M.P., Mills, P.L., 2014. Chapter One - Challenges in Reaction Engineering Practice of Heterogeneous Catalytic Systems, in: Anthony, G.D. (Ed.), Advances in Chemical Engineering. Academic Press, pp. 1-40.

- Georgianna, D.R., Mayfield, S.P., 2012. Exploiting diversity and synthetic biology for the production of algal biofuels. Nature 488, 329-335.

- Greenwell, H.C., Laurens, L.M.L., Shields, R.J., Lovitt, R.W., Flynn, K.J., 2010. Placing microalgae on the biofuels priority list: a review of the technological challenges. Journal of The Royal Society Interface 7, 703-726.

- Groen, J.S., 2004. Scales and Structures in Bubbly flows, Ph.D Thesis. Technische Universiteit Delft.

- Gupta, P., Al-Dahhan, M.H., Dudukovic, M.P., Toseland, B.A., 2001a. Comparison of singleand two-bubble class gas-liquid recirculation models - application to pilot-plant radioactive tracer studies during methanol synthesis. Chemical Engineering Science 56, 1117-1125.

- Gupta, P., Ong, B., Al-Dahhan, M.H., Dudukovic, M.P., Toseland, B.A., 2001b. Hydrodynamics of churn turbulent bubble columns: gas-liquid recirculation and mechanistic modeling. Catalysis Today 64, 253-269.

- Hamed, M., 2012. Hydrodynamics, Mixing and Mass transfer in Bubble Column with Internals, Ph.D Thesis. Washington University, Saint Louis, USA.

- Han, L., 2007. Hydrodynamics, back-mixing, \& mass transfer in a slurry bubble column reactor for fischer-tropsch alternative fuels, Ph.D Thesis, EECE. Washington University, Saint Louis.

- Han, L., Al-Dahhan, M.H., 2007. Gas-liquid mass transfer in a high pressure bubble column reactor with different sparger designs. Chemical Engineering Science 62, 131-139. 
- Hanagata, N., Takeuchi, T., Fukuju, Y., Barnes, D.J., Karube, I., 1992. Tolerance of microalgae to high CO2 and high temperature. Phytochemistry 31, 3345-3348.

- Harper, J.F., 1972. The Motion of Bubbles and Drops Through Liquids, in: Chia-Shun, Y. (Ed.), Advances in Applied Mechanics. Elsevier, pp. 59-129.

- Harteveld, W.K., 2005. Bubble columns: Structures or stability?, Ph.D Thesis, Applied Sciences. Technische Universiteit Delft, Delft.

- Henrard, A.A., de Morais, M.G., Costa, J.A.V., 2011. Vertical tubular photobioreactor for semicontinuous culture of Cyanobium sp. Bioresource Technology 102, 4897-4900.

- Hooshyar, N., van Ommen, J.R., Hamersma, P.J., Sundaresan, S., Mudde, R.F., 2013. Dynamics of Single Rising Bubbles in Neutrally Buoyant Liquid-Solid Suspensions. Physical Review Letters 110, 244501.

- Jacob-Lopes, E., Revah, S., Hernández, S., Shirai, K., Franco, T.T., 2009. Development of operational strategies to remove carbon dioxide in photobioreactors. Chemical Engineering Journal 153, 120-126.

- Jiang, X., Yang, N., Zhu, J., Yang, B., 2015. On the single and two-bubble class models for bubble column reactors. Chemical Engineering Science 123, 514-526.

- Joshi, J., Parasu Veera, U., Prasad, C.V., Phanikumar, D., Deshphande, N., Thakre, S., Thorat, B., 1998. Gas hold-up structure in bubble column reactors. PINSA-A 64, 441-567.

- Kantarci, N., Borak, F., Ulgen, K.O., 2005. Bubble column reactors. Process Biochemistry 40, 2263-2283.

- Kawase, Y., Tsujimura, M., Yamaguchi, T., 1995. Gas hold-up in external-loop airlift bioreactors. Bioprocess Engineering 12, 21-27.

- Klinthong, W., Yang, Y.-H., Huang, C.-H., Ta, C.-S., 2015. A Review: Microalgae and Their Applications in CO2 Capture and Renewable Energy. Aerosol Air Qual Res 15.

- Krichnavaruk, S., Powtongsook, S., Pavasant, P., 2007. Enhanced productivity of Chaetoceros calcitrans in airlift photobioreactors. Bioresource Technology 98, 2123-2130.

- Kumar, S.B., Moslemian, D., Dudukovic, M.P., 1997. Gas-holdup measurements in bubble columns using computed tomography. Aiche Journal 43, 1414-1425.

- $\quad$ Lau, R., Peng, W., Velazquez-Vargas, L.G., Yang, G.Q., Fan, L.S., 2004. Gas-Liquid Mass Transfer in High-Pressure Bubble Columns. Industrial \& Engineering Chemistry Research 43, 1302-1311.

- Lee, B.W., Dudukovic, M.P., 2014. Determination of flow regime and gas holdup in gas-liquid stirred tanks. Chemical Engineering Science 109, 264-275. 
- Lee, B.W., Dudukovic, M.P., 2015. A probabilistic model for correcting the directional sensitivity of optical probe measurements. AIChE Journal 61, 3516-3527.

- Levich, V.G., 1962. Physicochemical Hydrodynamics. Prentice Hall, New York.

- Luo, H.-P., 2005. Analyzing and Modelling of Airlift Photobioreactors for Microalgal and Cynobacteria Cultures, Ph.D Thesis. Washington University.

- Manjrekar, O., Dudukovic, M.P., 2013. Hydrodynamics and Mass Transfer in a Bubble Column with Internals, AIChE annual meeting, San Francisco, CA.

- Manjrekar, O.N., 2016. Hydrodynamics and Mass Transfer in Bubble Columns, Ph.D Thesis, Energy Environmental and Chemical Engineering. Washington University, Saint Louis.

- Manjrekar, O.N., Dudukovic, M.P., 2015. Application of a 4-point optical probe to a Slurry Bubble Column Reactor. Chemical Engineering Science 131, 313-322.

- Markou, G., Nerantzis, E., 2013. Microalgae for high-value compounds and biofuels production: A review with focus on cultivation under stress conditions. Biotechnology Advances 31, 15321542.

- Mayfield, S., Wong, P.K., 2011. Forum Chemical engineering: Fuel for debate. Nature 476, 402403.

- Miron, A.S., Camacho, F.G., Gomez, A.C., Grima, E.M., Chisti, Y., 2000. Bubble-column and airlift photobioreactors for algal culture. Aiche Journal 46, 1872-1887.

- Miyahara, T., Hamaguchi, M., Sukeda, Y., Takahashl, T., 1986. Size of bubbles and liquid circulation in a bubble column with a draught tube and sieve plate. The Canadian Journal of Chemical Engineering 64, 718-725.

- Mudde, R.F., 2005. Gravity-Driven Bubbly Flows. Annual Review of Fluid Mechanics 37, $393-$ 423.

- Mudde, R.F., Harteveld, W.K., van den Akker, H.E.A., 2009. Uniform Flow in Bubble Columns. Industrial \& Engineering Chemistry Research 48, 148-158.

- Mueller, S.G., 2010. Optical Measurements in Gas-Liquid Stirred Tanks, Ph.D Thesis. Washinton University, Saint Louis, USA.

- Nedeltchev, S., Jordan, U., Schumpe, A., 2007. Correction of the penetration theory based on mass-transfer data from bubble columns operated in the homogeneous regime under high pressure. Chemical Engineering Science 62, 6263-6273.

- Nedeltchev, S., Jordan, U., Schumpe, A., 2010. Semi-theoretical prediction of volumetric mass transfer coefficients in bubble columns with organic liquids at ambient and elevated temperatures. Canadian Journal of Chemical Engineering 88, 523-532. 
- Richmond, A., Cheng-Wu, Z., 2001. Optimization of a flat plate glass reactor for mass production of Nannochloropsis sp. outdoors. Journal of Biotechnology 85, 259-269.

- Skjånes, K., Rebours, C., Lindblad, P., 2012. Potential for green microalgae to produce hydrogen, pharmaceuticals and other high value products in a combined process. Critical Reviews in Biotechnology 33, 172-215.

- Torzillo, G., Pushparaj, B., Bocci, F., Balloni, W., Materassi, R., Florenzano, G., 1986. Production of Spirulina biomass in closed photobioreactors. Biomass 11, 61-74.

- Vandu, C.O., Koop, K., Krishna, R., 2004a. Large bubble sizes and rise velocities in a bubble column slurry reactor. Chemical Engineering \& Technology 27, 1195-1199.

- Vandu, C.O., Koop, K., Krishna, R., 2004b. Volumetric mass transfer coefficient in a slurry bubble column operating in the heterogeneous flow regime. Chemical Engineering Science 59, 5417-5423.

- Wu, C., 2007. Heat Transfer and Bubble Dynamics In A Slurry Bubble Column For FicherTropsch Alternative Fuels, Ph.D Thesis. Washington University, Saint Louis, USA.

- Xiao, Q., Yang, N., Li, J., 2013. Stability-constrained multi-fluid CFD models for gas-liquid flow in bubble columns. Chemical Engineering Science 100, 279-292.

- Xu, T., Jiang, X., Yang, N., Zhu, J., 2015. CFD simulation of internal-loop airlift reactor using EMMS drag model. Particuology 19, 124-132.

- Xue, J., 2004. Bubble velocity, size and interfacial area measurements in bubble columns, Ph.D Thesis, Energy Environmental and Chemical Engineering Washington University, Saint Louis.

- Youssef, A.A., Hamed, M.E., Grimes, J.T., Al-Dahhan, M.H., Dudukovic, M.P., 2013. Hydrodynamics of Pilot-Scale Bubble Columns: Effect of Internals. Industrial \& Engineering Chemistry Research 52, 43-55. 